\title{
Analysis of serum ferritin levels in non-diabetic, prediabetic and diabetic individuals
}

\author{
Chandrika N. ${ }^{1, *}$, Usha S.M.R. ${ }^{2}$ \\ ${ }^{\mathbf{1}}$ Assistant Professor, ${ }^{2}$ Professor \& HOD, Dept. of Biochemistry, ${ }^{1}$ Chamarajanagar Institute of Medical Sciences, \\ Karnataka, ${ }^{2}$ Rajarajeshwari Medical College and Hospital, Bengaluru, India
}

*Corresponding Author:

Email: dr.chandrikar@gmail.com

\begin{abstract}
Introduction: Type 2 diabetes mellitus (T2DM) is characterized by impaired insulin secretion, insulin resistance or both. In the initial asymptomatic phase there is hyperinsulinemia, as insulin resistance progress and beta cell function deteriorates 'Prediabetes' an intermediate hyperglycemic state prone for diabetic complications ensues. A chronic sub-clinical inflammation is associated with insulin resistance and it can be assessed using a proinflammatory marker like serum ferritin

Aim: We intend to evaluate serum ferritin levels in normoglycemics, intermediate hyper glycemics and overt cases of T2DM and also to investigate if any correlation exists between blood glucose and serum ferritin levels at these three different stages of glycemia.

Materials and Methods: In accordance with World health organisation guidelines, we inducted forty seven prediabetics and thirty seven T2DM patients in the first and second groups of our study respectively. Twenty three healthy controls constituted the third group. Serum ferritin, fasting and 2 hour postprandial blood glucose were estimated in all subjects.

Results: The mean \pm SD of Log serum ferritin levels in prediabetic, diabetic group and Controls groups are $4.21 \pm 0.96,4.25 \pm 1.07$ and $3.59 \pm 0.95 \mu \mathrm{g} / \mathrm{L}$ respectively. Mean Log serum ferritin levels is significantly higher in pre-diabetics and diabetics with $\mathrm{p}=0.012$. A positive and statistically significant association was noticed between serum ferritin and blood glucose levels when the subjects of the three groups were considered together $(\mathrm{p}=0.036)$ but not when the groups were considered separately.

Conclusion: Serum ferritin levels are elevated in prediabetes and T2DM when compared to healthy controls and it reflects the inflammation associated with prediabetes and T2DM.
\end{abstract}

Keywords: Blood glucose, Inflammation, Prediabetes, Serum ferritin, Type 2 diabetes mellitus.

Received: $12^{\text {th }}$ October, 2017

\section{Introduction}

Diabetes mellitus, a syndrome complex, has emerged as a major health issue across the globe. According to International Diabetes Federation 2015 report, 415 million people worldwide have this disease and India harbours 69.1 million, the second highest number of diabetics in the world. Type 2 Diabetes mellitus (T2DM) is the most prevalent form of diabetes. ${ }^{1}$ It is characterised by insulin resistance, impaired insulin secretion, or both. T2DM has a long asymptomatic preclinical phase which goes undetected. Individuals with undetected T2DM are at significantly higher risk for stroke, coronary artery disease and peripheral vascular disease. Overall for every person with diagnosed diabetes there is another who has undiagnosed T2DM. ${ }^{1}$ This is because in the initial stages of the disorder glucose tolerance remains near-normal, despite insulin resistance, as the pancreatic beta cells compensate by increasing insulin output. A gradual fall in beta cell function ensues, when an intermediate hyperglycemic state of either Impaired Fasting Glucose (IFG) or Impaired Glucose Tolerance (IGT) results which are collectively classified under the term 'Prediabetes'. The complications of diabetes are induced during this phase. The disease ultimately progresses towards complete beta cell failure leading to overt diabetes. ${ }^{2}$

Inflammation has been suggested to play a central role in the pathogenesis of diabetes and atherosclerosis. $^{3} \quad$ Accumulating evidence indicates that chronic sub-clinical inflammation is associated with insulin resistance. ${ }^{4}$

The obesity accompanying type 2 diabetes mellitus, particularly in a central or visceral location is thought to be part of the pathogenic process. Adipocyte products and adipokines produce an inflammatory state. The increased production of free fatty acids and some adipokines may cause insulin resistance in skeletal muscle and liver. $^{2}$ The systemic inflammation coexisting with diabetes can be assessed by estimating a simple pro- 
inflammatory marker like serum ferritin. Ferritin is cell's storage compartment for iron and its role as a tool to diagnose iron deficiency anemia is established beyond doubt. Ferritin with relatively poor iron content is present in the serum in concentrations roughly proportional to total body iron stores. ${ }^{5}$ Many studies have reported an elevated serum ferritin levels in T2DM. ${ }^{6,7}$ In this effect the possibility of a causal association of serum ferritin in T2DM cannot be ruled out.

In an effort to know the same we have undertaken this study to evaluate serum ferritin levels in normoglycemics, intermediate hyperglycemics and overt cases of T2DM. Our aim also includes to investigate if any correlation existed between blood glucose and serum ferritin levels at these three different stages of glycemia.

\section{Materials and Methods}

This study was conducted at Rajarajeswari Medical College and Hospital, Bengaluru. The individuals in the study were between 20 and 60 years of age. It involved three groups. Forty seven individuals diagnosed with prediabetes based on WHO criteria constituted the first group. Accordingly subjects having Impaired fasting glucose [Fasting blood glucose between 110 $\mathrm{mg} / \mathrm{dl}$ and $125 \mathrm{mg} / \mathrm{dl} ; 2$ hour Post-prandial blood glucose less than $140 \mathrm{mg} / \mathrm{dl}$.] or Impaired glucose tolerance [Fasting blood glucose less than 126 $\mathrm{mg} / \mathrm{dl}$; 2 hour Post-prandial blood glucose between $140 \mathrm{mg} / \mathrm{dl}$ and $199 \mathrm{mg} / \mathrm{dl}$ ] or both were included in this group. The second group consisted of thirty seven individuals diagnosed with T2DM, again as per WHO guidelines ${ }^{8}$. Care was taken to exclude individuals whose haemoglobin levels were below $12 \mathrm{~g} / \mathrm{dl}$ and also those with acute or chronic inflammation or infective diseases in both these groups. The other exclusion criteria was pregnancy. We inducted twenty three age and sex matched healthy individuals as controls under the third group. The study was approved from the Institutional ethics committee. An informed consent was obtained from all the participants of the study.

A fasting and 2 hour post prandial venous blood samples were collected under all aseptic precautions from all the study subjects. Fasting blood glucose (FBG) and post prandial blood glucose (PPBG) was estimated on fully automated analyzer from Transasia Company, ERBA EM 360. Serum ferritin were analyzed on Mindray BS 300 automated instrument by latex enhanced Immunoturbidimetric method.

\section{Statistical Analysis}

Descriptive and inferential statistical analysis has been carried out in the present study. Results on continuous measurements are presented on Mean \pm SD (Min-Max). Significance is assessed at 5\% level of significance. Analysis of variance (ANOVA) has been used to find the significance of study parameters between three or more groups of patients.

\section{Results}

The study is basically targeted to analyse the serum ferritin behaviour in the three groups representing different stages of glycemia. Table 1 is compilation of mean and Standard deviation (SD) of the three biochemical parameters studied in these groups. The normal reference interval of serum ferritin has a wide range because of age and gender variations. ${ }^{9}$ The reference range for adult male is between $20-270 \mu \mathrm{g} / \mathrm{L}$ and that of adult female is $10-120 \mu \mathrm{g} / \mathrm{L}$. In the current study also we have observed that the distribution of ferritin was positively skewed. We therefore presented ferritin in natural $\log$ terms. Table 1 also includes the mean \pm SD value of $\log$ serum ferritin in all the three groups. Mean Log serum ferritin levels is significantly higher in prediabetics and diabetics with $\mathrm{p}=0.012$.

Table 1: Comparison of mean \pm SD of FBG, PPBG and serum ferritin in three groups studied

\begin{tabular}{|l|c|c|c|c|}
\hline & Prediabetics & Diabetics & Healthy Controls & p value \\
\hline FBG $(\mathrm{mg} / \mathrm{dl})$ & $106.30 \pm 13.05$ & $165.8 \pm 74.15$ & $89.03 \pm 11.83$ & $0.006^{* *}$ \\
\hline PPBG $(\mathrm{mg} / \mathrm{dl})$ & $165.43 \pm 18.03$ & $252.30 \pm 88.63$ & $106.77 \pm 12.78$ & $<0.001^{* *}$ \\
\hline Serum ferritin $(\mu \mathrm{g} / \mathrm{L})$ & $94.67 \pm 71.74$ & $113.78 \pm 130.73$ & $54.79 \pm 50.95$ & 0.059 \\
\hline Log $($ Serum ferritin $(\mu \mathrm{g} / \mathrm{L})$ & $4.21 \pm 0.96$ & $4.25 \pm 1.07$ & $3.59 \pm 0.95$ & $0.032^{*}$ \\
\hline
\end{tabular}

$* \mathrm{P}$ value $=0.05$ suggest significance, $* * \mathrm{P}<0.01$ level suggests strong significance

In the study we correlated serum ferritin levels with blood glucose levels estimated in the fasting and 2 hour post prandial blood samples. Table 2 represents the correlation analysis of serum ferritin against FBG and PPBG in the different groups of our study. 
Table 2: Pearson correlation of serum ferritin against FBG and PPBG levels in three groups studied

\begin{tabular}{|c|c|c|c|c|c|c|c|c|}
\hline Pair & \multicolumn{2}{|c|}{ Overall } & \multicolumn{2}{c|}{ Prediabetics } & \multicolumn{2}{c|}{ Diabetics } & \multicolumn{2}{c|}{ Healthy Controls } \\
\hline \multirow{2}{*}{ Serum ferritin v/s FBG } & $\mathrm{r}$ & $\mathrm{p}$ value & $\mathrm{r}$ & $\mathrm{p}$ value & $\mathrm{r}$ & $\mathrm{p}$ value & $\mathrm{r}$ & $\mathrm{p}$ value \\
\cline { 2 - 9 } & .203 & $.036^{*}$ & .140 & .349 & .135 & .197 & -.113 & -.120 \\
\hline Serum ferritin v/s PPBG & .263 & $.006^{* *}$ & .099 & .509 & .425 & .242 & .608 & .586 \\
\hline
\end{tabular}

Note:' $r$ ' is Pearson's correlation and ' $p$ ' is two tailed significance

**Correlation is significant at 0.01 (2-tailed): * Correlation is significant at 0.05 (2-tailed)

\section{Discussion}

The impact of type 2 Diabetes mellitus on economic and social well-being of a country like India is too overwhelming to be ignored. The macrovasular complications of the T2DM sets in even before the disease manifests ${ }^{10}$. So screening for T2DM will not only help to keep surveillance of the population but will also identify individuals with prediabetes who may benefit from interventions to prevent or delay the progression of the disease and its complications.

Ever since the 'common soil hypothesis' was put forth by Micheal P.Stern ${ }^{11}$ many studies have successfully reported that a chronic systemic inflammation is associated with the development of both insulin resistance and atherosclerosis, ${ }^{12,13}$ though the pathophysiology has not been clearly understood till date. This emphasises the need to estimate a proinflammatory marker along with blood glucose during a diabetic screening. Whether the inflammatory marker levels vary with progression of the disease is another aspect that has to be explored.

In the present study we chose to analyse serum ferritin, for the fact that iron and glucose metabolism are interlinked ${ }^{14}$. And ferritin maybe an apt tool to look for association between glucose levels and inflammation. Here are the observations we made in our study.

The principal biochemical parameter of our study, serum ferritin shows significant variation $(p=0.032)$ when compared between the three groups of our study. The mean $\pm \mathrm{SD}$ of $\log$ serum ferritin levels in prediabetic, diabetic group and controls groups are $4.21 \pm 0.96,4.25 \pm$ 1.07 and $3.59 \pm 0.95 \mu \mathrm{g} / \mathrm{L}$ respectively. Mean $\log$ serum ferritin levels is significantly higher in prediabetics and diabetics with $\mathrm{p}=0.012$. Many studies that have shown an elevated serum ferritin levels in diabetes and prediabetes. Rui Jiang et al in their prospective study have noticed that serum ferritin levels were increased in women who developed T2DM when compared to healthy controls. ${ }^{15}$ Similarly, Forouhi N.G. et al have also observed elevated serum ferritin levels was predictive of T2DM in their research work. ${ }^{16}$ In both the studies serum ferritin has shown as moderate elevation, within its reference range as seen in our study. Serum ferritin values were found to be high in prediabetes when compared to healthy subjects in reports published

by Faranak Sharifi et al and Ching Lung Cheung et al, thus supporting the findings in our study. ${ }^{17,18}$ A project involving estimation of ferritin in three groups of normoglycemia, intermediate hyperglycemia and diabetes as in our study was undertaken by Chu-Hee kim et al, among Korean men and women. While they observed serum ferritin concentrations being highest in the DM group, followed by the IFG group and the normal fasting glucose (NFG) group, in both men and women $(186 \pm 127,176$ \pm 108 , and $156 \pm 92 \mathrm{ng} / \mathrm{mL}$, respectively, in men; $85 \pm 62,75 \pm 55$, and $59 \pm 47 \mathrm{ng} / \mathrm{mL}$, respectively, in women), ${ }^{19}$ we noticed $94.67 \pm$ $71.74,113.78 \pm 130.73$ and $54.79 \pm 50.95 \mu \mathrm{g} / \mathrm{L}$ respectively. There are striking similarities between their findings and our findings.

We correlated serum ferritin with the blood glucose levels, a positive and statistically significant association was noticed between the two, when the subjects of the three groups were considered together [Serum ferritin v/s FBG $(p=0.036)$ and Serum ferritin v/s PPBG $(\mathrm{p}=0.006)]$ but not when the groups were considered separately.

The above findings asserts the role of iron in glucose metabolism. Multiple theories have been put forth to explain the same. The triggering factors like visceral obesity, low anti-oxidant state sets in a cascade of insidious low grade inflammatory process which release cytokines. Cytokines simultaneously cause an increase in transferrin receptors on the cell surface, favouring tissue deposition of iron. This leads to elevated ferritin levels. Normally the heavy chain in the apoferritin molecule exerts ferroxidase activity, catalyzing the oxidation of ferrous $\left(\mathrm{Fe}^{2+}\right)$ into ferric $\left(\mathrm{Fe}^{3+}\right)$, but during oxidative stress, the ferroxidase activity in the heavy chain is downregulated decreasing the incorporation of iron into ferritin, resulting in the availability of free iron. Free iron is capable of generating hydroxyl radical and other reactive oxygen species which damage the beta cells of the 
pancreas hampering insulin synthesis and secretion ${ }^{14}$.Iron deposition in the muscles decrease glucose uptake in the muscle and in the liver iron interferes with hepatic insulin extraction contributing to insulin resistance. ${ }^{15}$ One of the studies reports that iron also interferes with insulin signalling. ${ }^{20}$ These mechanisms suggest that the iron plays a causal role in etiology and pathophysiology of type 2 diabetes mellitus.

To conclude, owing to paucity of studies involving ferritin and diabetes in South Indian population, we took up this pilot study. Serum ferritin levels are elevated in prediabetes and T2DM when compared to healthy individuals. Based on our findings we are of the opinion that serum ferritin levels reflects inflammation associated with prediabetes and T2DM. We recommend the study to be undertaken in larger group to check the reliability and utility of serum ferritin as a tool to detect and monitor the progression of pro-inflammatory changes in T2DM.

\section{References}

1. International Diabetes Federation, Diabetes Atlas, 7th edition, 2015.

2. Powers AC. Diabetes Mellitus: Diagnosis, classification and pathophysiology. In: Kasper DL, Fauci AS, Hauser SL, Longo DL, Jameson JL, Loscalzo MD.(eds.) Harrison's Principles of Internal Medicine. $19^{\text {th }}$ edition. New York. McGraw Hill. 2015. p.2404-5.

3. Sabanayagam C, Shankar A, Lim SC, Lee J, Tai ES and Wong TY. Serum C-reactive protein level and prediabetes in two Asian populations. Diabetologia. 2011; Vol.54:767-75.

4. Haffner SM. Pre-diabetes, insulin resistance, inflammation and CVD risk. Diabetes Research and Clinical Practice.2003;Vol.61:S9-18.

5. Higgins T, Beutler E, Doumas BT. Hemoglobin, Iron and bilirubin, In: Burtis CA, Ashwood ER, Bruns DE.(eds.) Teitz Fundamentals of Clinical Chemistry. $6^{\text {th }}$ edition. Elsevier.p516-20.

6. Tuomainen TP, Nyyssonen K, Salonen R et al. Body iron stores are associated with serum insulin and blood glucose concentration: population study in 1,013 eastern Finnish men. Diabetes Care 1997;20:426-8.

7. Ford ES, Cogswell ME. Diabetes and serum ferritin concentration among US adults. Diabetes Care 1999;22:1978-83.

8. World Health Organisation. Definition and diagnosis of diabetes mellitus and intermediate hyperglycemia. Availble from: http://www.who.int/diabetes/publications/Definiti on and diagnosis of diabetes. Accessed on 05.10.2017.

9. WHO. Serum ferritin concentrations for the assessment of iron status and iron deficiency in populations. Vitamin and Mineral Nutrition Information System. Geneva, World Health Organization, 2011
(WHO/NMH/NHD/MNM/11.2) Available from: http://www.who.int/vmnis/indicators/serum_ferrit in.pdf, Accessed on 05.10.2017.

10. Deedwania PC, Fonseca VA. Diabetes, prediabetes and cardiovascular risk: Shifting the paradigm. The American Journal of Medicine. 2005;118:939-47.

11. Stern MP. Diabetes and cardiovascular disease: The "common soil" hypothesis.

Diabetes. 1995;44(4): 369-74.

12. Shoelson SE, Lee J, and Goldfine AB. Inflammation and insulin resistance. The Journal of Clinical Investigation. 2006;116(7):1793-801.

13. Zeyda M, Stulnig TM. Obesity, Inflammation, and Insulin resistance. Gerontology. 2009;55:37986.

14. Fernandez-Real JM, Bermejo AL, Ricart W. Cross-Talk between Iron Metabolism and Diabetes Diabetes. 2002;51:2348-54.

15. Jiang R, Manson JE, Meigs JB, Ma J, Rifai N, Hu FB. Body Iron Stores in Relation to Risk of Type 2 Diabetes in Apparently Healthy Women. JAMA. 2004;291(6):711-7.

16. Forouhi NG, Harding AH, Allison M, Sandhu MS, Welch A, Luben R, Bingham S, Khaw KT, Wareham NJ.. Elevated serum ferritin levels predict new-onset type 2 diabetes: results from the EPIC-Norfolk prospective study. Diabetolgia. 2007;50(5):949-56.

17. Sharifi F, Nasab NM and Zadeh HJ. Elevated serum ferritin concentrations in prediabetic subjects. Diabetes and Vascular Disease Research.2008;5:15-8.

18. Cheung C-L, et al. High ferritin and low transferrin saturation are associated with prediabetes among a national representative sample of U.S. adults. Clinical Nutrition. 2013. http://dx.doi.org/10.1016/j.clnu.2012.11.024

19. Kim CH, Kim HK, Bae SJ, Park JY, Lee KU. Association of elevated serum ferritin concentration with insulin resistance and impaired glucose metabolism in Korean men and women Metabolism.2011. Vol 60(3):414-20.

20. Liu B, Xuan X, Liu J, Li F and Yin F, The Relationship between Serum Ferritin and Insulin Resistance in Different Glucose Metabolism in Nonobese Han Adults. International Journal of Endocrinology 2015. Article ID 642194, 5 pages. Doi:10.1155/2015/642194. 